\title{
Teaching Process and Product: Crafting and Responding to Student Writing Assignments*
}

\author{
Pamela A. Zeiser, University of North Florida
}

\begin{abstract}
$A$ long with the classroom setting Aand lecture format, essay exams and term papers are often the norm in undergraduate political science courses. But are either conducive to learning the intricacies of political science, critical inquiry, or effective writing? These skills are required of students going on to graduate school and the latter two are important to any career choice, yet the writing

In composing formal papers, they write to a teacher, who grades them on the perfection of their final draft. While students do learn and process information in performing these assignments, none of these school writing assignments promotes writing primarily for the sake of the learner, and none of them encourages students to make school knowledge personally their own. $(1982,22)$
\end{abstract} assignments for most undergraduate courses fail to develop them. Essay exams are generally graded for content, which students don't always retain, and they are single-draft assignments. Terms papers are frequently last-minute, one-draft efforts. Moving beyond these standard assignments-requiring students to write to learn-allows instructors to provide students with opportunities to develop the abilities they will need to succeed in political science or any other discipline or profession. Doing so also provides professors with a variety of interesting assignments to give and to grade.

Writing is a recursive process. When we write articles for publication or papers for conferences, we go through a process of thinking, writing, and revising, followed by more thinking, more writing, and more revising. In this way, we develop and improve our critical thinking and writing abilities. Yet, professors rarely ask their students to do the same. We typically treat writing as a product rather than a process. By doing so, we fail to teach students the benefits of drafting and revising. Toby Fulwiler (1982) concluded that

in essay examinations, [students] demonstrate how much they know.

Pamela A. Zeiser is an assistant professor of political science and public administration at the University of North Florida. She currently teaches international relations and comparative politics. She was a writing instructor for four years.
There are two stages to effective writing assignments: crafting and responding. Crafting instructive, creative political science writing assignments requires building several short assignments into a syllabus, making those assignments different but related, and providing students with clear guidelines. Responding effectively to writing assignments depends on creatively managing time pressures, evaluating writing as a part of a process, being aware of student reactions to comments, and providing clear, helpful comments related to the grade.

\section{Crafting Writing Assignments in Political Science}

Writing assignments in political science are most often designed to "test students' knowledge of a subject ... [not to] help students learn more about a subject" (Holder and Moss 1988; emphasis in original). Typical writing assignments are, therefore, often one-draft efforts. This shortchanges students because writing skills are best developed and improved by frequent, if not daily, writing. We can help our students learn more about political science and writing by building either multiple-draft or several short assignments into a course syllabus. Giving writing assignments early in the semester will allow instructors to diagnose students' writing problems and identify students who will need additional help from a writing center or writing course. Such an assignment will also allow students to receive more feedback. Neither we nor the students gain much from our respective efforts if students hand in papers only at the end of the semester. Students may never look at those papers-and our commentsagain. Even when students do review our comments on term papers or finals, they have little incentive to apply that advice when writing papers for other courses.

Short, frequent writing assignments are particularly effective when they are different but related. A series of assignments that build one upon the other serves two purposes. First, it makes the thinking and writing process visible to students. We can show students the individual and cumulative steps to take in comprehensively analyzing a topic and developing a complete, thoughtful paper. Second, it teaches students the benefits of revision and seeking and responding to feedback.

The writing assignments for my Introduction to International Relations course illustrate this. Like many such courses, mine is structured around the basic schools of thought: idealism, realism, globalism, and structuralism/Marxism. The first writing assignment is designed to enable students to better understand these schools of thought. I ask students to write a 2-3 page paper in which they (1) accept the premises of each approach and list ideas and examples that support them and (2) doubt the validity of these ideologies and provide ideas and examples that cannot be explained or even contradict each approach. Responding to this assignment, given very early in the semester, gives me an opportunity to assess students' writing skills and determine their understanding of basic schools of thought in international relations. I can encourage students with serious writing problems 
to seek additional help, and I can assist students having difficulty with the content either one-on-one or by repeating lectures.

The second assignment is a $2-3$ page paper in which I ask students to explore the school of thought they believe best permits explanation of past and current world events and provide examples to support their position. This assignment allows me to judge improvements in writing as well as understanding of content and to assess students' abilities to take and support a particular position. A third, 4-6 page assignment requires students to utilize the approach they prefer to briefly analyze a current event.

Cumulatively, successful students will have demonstrated an understanding of substantive content, evaluated the usefulness of an approach from a personal but supported position, and used that approach to analyze a global issue of importance to them. Instead of getting one chance to display their subject knowledge and ability to communicate in the form of a single $8-10$ page term paper or an essay exam, students will have had the opportunity to write many papers with the benefit of my comments on earlier assignments.

Hols (1990) suggested requiring political science students to keep journals. For example, having students each choose a country and keep a semester-long account of U.S. foreign policy toward that country. Journal entries can consist of reactions to news broadcasts, newspapers, news magazines, books, scholarly journals, government documents, public lectures, or events. Professors can evaluate student progress in a number of ways, including collection and assessment, small-group peer review, or a few minutes of in-class discussion to ensure students are up-to-date on current affairs. In addition to encouraging frequent writing and continuous knowledge-gathering, journals can be used in conjunction with other writing assignments. Take-home or in-class writing exercises could require students to relate course concepts and readings to their selected countries. Or the professor could ask students to develop term papers (with students turning in at least two drafts) from their ongoing accounts of U.S. foreign policy toward their countries. A third option is to have students write opinion letters to elected officials based on a current bill or issue relevant to their countries.

Periodic journal reviews by the professor permit identification of students not doing the assignments, students with writing difficulties, and students who need to dig deeper into their selected topic. Effective writing assignments develop students' abilities rather than simply test them.

To ensure their effectiveness, clear guidelines must accompany assignments. Preparing such guidelines requires asking: What is the purpose of the assignment? What skills do I want students to demonstrate? What criteria will I use to determine success? Will I provide feedback without giving a grade or will I grade the assignment? What do I want students to do and is what I want them to do interesting and appropriate? How does the assignment relate to what comes before it and after it in the course? Have I given students all necessary information (subject, purpose, form, mode, audience, tone)? The answers to these questions need to be provided to students. Giving students a scoring guide that spells out and weights the components of a strong paper (e.g., strong thesis, relevance to course concepts/reading, effective use of ideas/examples, acceptable number of grammar errors, proper citations, and so forth) will benefit everyone (Brinko 1991; Holder and Moss 1988; Lindemann 1982). The more clearly professors and students understand a writing assignment, the more likely both are to find it a useful learning experience.

\section{Responding to Writing Assignments in Political Science}

Many professors avoid writing assignments because of the time commitment involved. The time commitment is significant, but need not be onerous. Evaluating assignments is a three-stage process. In the first stage, preevaluation, instructors should remind themselves of the instructions, guidelines, and objectives of the assignment; determine how much time there is to mark the papers; and define their objectives in marking the papers. While actually reading, marking, and grading papers, instructors need to think about the particular components of each paper that should be marked, the comments and feedback that will be most helpful to students, and the established grading standards. After grading the papers, instructors should consider what they can do to "point students in the right direction" as the papers are returnedone of the few times a professor may have the full, rapt attention of all students (Holder and Moss 1988).

The preevaluation stage can be the briefest, especially if professors have already communicated clear guidelines to students. The time spent developing the assignment guidelines does not need to be repeated. Instructors do, however, need to be sure to adhere to the guidelines. The third stage, postevaluation, is also short. Professors need only decide what to tell students generally about how the papers matched or failed to match expectations.

The second stage is the lengthiest, but also allows for the most creativity. For example, an instructor can choose to not evaluate the papers herself. Peer review activities are especially effective for multiple-draft assignments, but can be used for other types of assignments as well. One common technique is to have students form peer review groups. This benefits writers by letting them receive feedback from several readers and benefits readers by giving them practice at critical reading and constructive criticism. In a similar manner, organizing writing clinics can lessen the time an instructor spends marking early drafts. Especially useful in large classes, students in clinics focus on reproduced excerpts from, or several complete anonymous drafts of, student papers and join in small groups to discuss strengths and weaknesses. For any 
peer review activity, the professor should direct student efforts by developing and distributing guide sheets of suggested response criteria.

When evaluating papers, instructors must evaluate writing as part of a process, be aware of student reactions to professor comments, and provide clear, helpful comments. Mark early drafts and papers strategically. On the first paper, it may be best to provide feedback without giving grades. Focus on two or three main areas needing improvement. Students react poorly to papers that have been liberally splashed with red ink. Limiting comments improves the likelihood that students will attempt to improve the paper and saves the instructor time. Other areas needing improvement can be dealt with in turn. Just as writing is a process, so is the act of improving writing.

Treating writing as a process and knowing how students react to professors' comments can help instructors effectively communicate with students, making the time spent on evaluation more efficient. Studies show that students like a combination of margin and summary comments because it gives them a sense of dialogue, a sense that the reader is talking with them. Students also like specific questions that make them think about the points they

\section{Note}

* Thank you to Kimberlee Gillis-Bridges, Lissa Peterson, and Janet Retseck, with were trying to make; this is especially important on "Good/A" papers, when students still expect more than a note saying "good job." Students also respond well to genuine positive responses throughout the paper. Rather than leading into a discussion of weaknesses with vague compliments, instructors should offer students clear appraisals of what has been done well and why (Smith 1989).

Too many professors fail to provide clear, helpful comments related to the grade. In "Is There a Text in This Grade?" Felicia Mitchell (1994) reported the results of a study in which she mailed colleagues a student paper that met all the criteria for a failing grade. The student did not engage the topic; had committed errors of fact, grammar, spelling, usage, and punctuation; and had not cited sources, even though the assignment called explicitly for the use of secondary sources. Most of the 17 professors who responded gave the paper a $\mathrm{D}$, but the range was from F to B. More telling, however, were the written comments, which focused first on grammar and usage, then on organization and style, and lastly on content. Mitchell discovered that, all too often, professors respond to surface problems rather than ones with content and structure. Most of the professors offered

whom I team-taught workshops on Writing Strategies for College Instructors of Political advice on editing, as if all the student needed to do was correct mistakes. To avoid focusing on superficial errors while ignoring more serious content and writing difficulties, writing teachers often suggest that, when grading each paper, instructors comment first on content, second on structure, and third on style and grammar. Clear comments that express the reasons the instructor has for giving a grade and clearly delineate the areas needing improvement better help students to understand their content and writing weaknesses.

Often, writing is seen as a product, as something on paper that can be inserted, deleted, reorganized, or corrected (Mitchell 1994). Professors need to reinforce to students that writing is a process, a written version of an actively thought-about idea or topic. If the writing does not communicate that idea, it is not a final product. Surface revisions will not solve the problem. A student may need to significantly revise a piece of writing until it communicates what he or she is trying to say. If instructors keep this in mind when designing and evaluating writing assignments, they can direct students so that they learn not only the substance of political science but also become more competent writers.

\section{References}

Brinko, Kathleen T. 1991. "Visioning Your Course: Questions to Ask as You Design Your Course." The Teaching Professor 5(February): 3-4.

Fulwiler, Toby. 1982. "Writing: An Act of Cognition." In New Directions for Teaching and Learning: Teaching Writing in All Disciplines, ed. C.W. Griffin. San Francisco: Jossey-Bass.
Holder, Carol, and Andrew Moss. 1988. Improving Student Writing. Pomona, CA: California State Polytechnic University.

Hols, Wilbert G. 1990. "A Versatile and Fun Learning Experience: The Student Jour-' nal." Innovation Abstracts 12(October): $1-2$.

Lindemann, Erika. 1982. Rhetoric for Writing Teachers. Oxford: Oxford University Press.
Science and Economics at the Claremont Graduate University.
Mitchell, Felicia. 1994. "Is There a Text in This Grade? The Implicit Messages of Comments on Student Writing." Issues in Writing 6(Spring/Summer): 187-95.

Smith, Ernest. 1989. “'It Doesn't Bother Me, But Sometimes It's Discouraging': Students Respond to Teachers' Written Responses," Joumal of Teaching Writing 8(Special): 253-65. 